\title{
LA FRONTERA COMO MARGEN HETEROLÓGICO. EL TRIPARTITO ANDINO (BOLIVIA, PERÚ Y CHILE) Y EL ESPEJISMO ACADÉMICO SOBRE LOS "AYMARAS SIN FRONTERAS""
}

\author{
THE BORDER AS A HETEROLOGICAL MARGIN. THE ANDEAN TRIPARTITE \\ (BOLIVIA, PERU AND CHILE) AND THE ACADEMIC ILLUSION ABOUT \\ "AYMARAS WITHOUT BORDERS"
}

\author{
Sergio González Miranda**
}

\begin{abstract}
Se analiza la producción intelectual que surgió inspirada por la fundación de la organización "Alianza Estratégica Aymaras Sin Fronteras" (AEASF) en 2001. La AEASF, fundada en el poblado andino chileno de Putre, próximo a la triple frontera, reúne a 57 municipios rurales y fronterizos de Perú, Bolivia y Chile. El discurso de esta organización sugería la emergencia de una emancipación cultural y la toma de conciencia de su posición estratégica, transformando a la frontera como recurso político, pero dentro de la institucionalidad democrática existente en los tres países, y aprovechando las oportunidades financieras ofrecidas por organismos internacionales para la implementación de proyectos de desarrollo. Lo anterior sería interpretado por académicos y especialistas como la concreción de fenómenos propios de una nueva sociedad como la glocalización (Borja y Castells 1997). Sin embargo, en este artículo se pretende demostrar que ello solo fue un espejismo y que los procesos de marginalización y pobreza continuaron sin mayores cambios.
\end{abstract}

Palabras claves: Triple frontera, glocalización, emancipación cultural, posición estratégica.

It analyzes the intellectual output that came up inspired by the foundation of the organization "Aymaras without Borders Strategic Alliance" (AWBSA) in 2001. The AWBSA gathers together 57 rural and bordering municipalities of Peru, Bolivia and Chile founded in the Chilean Andean area in Putre, near the triple frontier. The message of this organization suggested the emergency of a cultural emancipation and the awareness of its strategical position, becoming the border as a political resource, but inside the democratic institutional framework in these three countries, and taking advantage of the financial opportunities offered by international organisms to introduce development projects. Above said would be understood by academicians and specialists as the precision of phenomena typical of a new society as glocalization (Borja and Castells 1997). However, it is expected to demonstrate in this article that it was not just an illusion and that the processes of marginalization and poverty continued without greatest changes.

Key words: Triple frontier, cultural emancipation, strategical position.

\section{Introducción}

En la meseta de Ancomarca confluyen Perú, Bolivia y Chile, ese punto georreferecial es conocido popularmente como tripartito. Corresponde al Hito 80 Chile-Perú e Hito 5 Bolivia-Chile (ver Mapa 1). Allí existe un pequeño obelisco con tres caras, cada una tiene dibujada la bandera de uno de estos países. Las caras del obelisco son como la máscara del dios Jano, una mira hacia el norte, otra hacia el oriente y la tercera hacia el sur, pero también miran hacia el pasado y hacia el futuro. Siempre la primera mirada parece ser la dominante en ese lugar caracterizado por lo tradicional, pero la segunda -supuestamente- comienza a tomar el bastón de mando producto de la presencia de organismos internacionales y flujos de mercancías de las zonas francas de Tacna e Iquique. Donde los actores principales serían los alcaldes andinos que "emprenden políticamente la frontera armando redes a escalas múltiples, tanto con los bancos internacionales como con los centros políticos y sus homólogos fronterizos" (Rouviere 2014:38).

Aunque la Historia nos pueda entregar no solo pistas o indicios, sino también conclusiones fundadas acerca de las limitaciones estructurales que tienen -para alcanzar el desarrollo- determinadas sociedades o comunidades que históricamente han estado marginalizadas, dominadas u oprimidas, sin embargo, cuando emergen nuevos fenómenos a gran

\footnotetext{
* Resultado Proyecto Fondecyt 1160209 y Proyecto UTA Mayor 5752/17.

** Universidad de Tarapacá, Arica, Chile. Correo electrónico: pampino50@gmail.com
} 


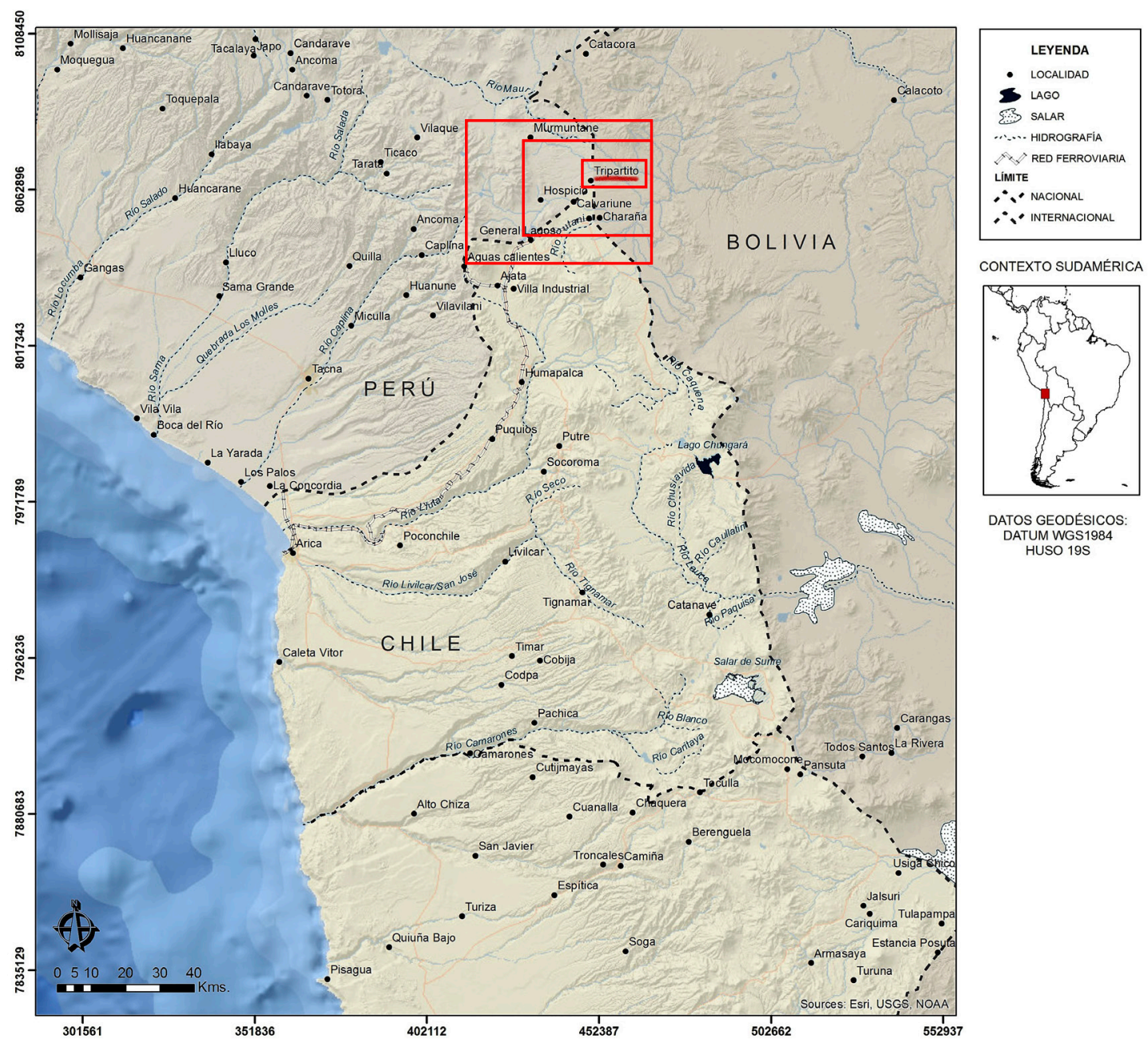

Mapa 1. Ubicación del Tripartito. Fuente: ESRI, USGS, NOAA.

escala -como ha sido la globalización- tendemos a pensar que se aproxima el deseado cambio social, cultural o político. Muchos autores imaginaron -a partir de la globalización- la emergencia de una nueva geografía, que "sucintamente descrita provocará en todos los países un nuevo ordenamiento territorial derivado de la lógica de expansión del capital desterritorializado que acompaña ahora a la segmentación de los procesos industriales en términos funcionales y territoriales" (Boisier 2003:29). Incluso se habló de virtualización de la economía y redes emergentes, incluyendo redes de ciudades y regiones asociativas de frontera (Wong-González 2004) ¿Podría este fenómeno de desterritorialización llegar hasta los espacios más apartados, invisibilizados y marginalizados, y llevar el desarrollo?

Este optimismo se vio aumentado con la promulgación del Convenio 169 de la OIT sobre Pueblos Indígenas y Tribales, donde el fenómeno de las fronteras surge con especial interés y fuerza, tanto porque puede cuestionar las fronteras estatales actuales como porque posibilita la alianza entre pueblos indígenas que habitan territorios asociativos de frontera. La pregunta es si esa asociación la realizan dentro de los marcos institucionales/ sistémicos o responde a un proyecto emancipatorio. Aranda y Salinas, además, ven en el Convenio 169 la posibilidad de "un protagonismo internacional inusitado a distintos grupos indígenas que tras su 
movilización internacional ven la posibilidad de reivindicar, dentro de otros aspectos, lo referido a los territorios ancestrales y sus usos. La novedad de esta iniciativa es que se trata de territorios transfronterizos" (2015:168).

Ello es lo que aconteció - a partir de 2001-con la creación en la triple frontera andina, de la organización llamada "Alianza Estratégica Aymaras Sin Fronteras" $(\mathrm{AEASF})^{1}$, a partir de la Feria Regional Andina (FERAN) en el pueblo de Putre, concretando una iniciativa e ideario iniciados en décadas anteriores en los tres países de forma dispersa y espontánea. Este fenómeno generó concomitantemente una importante producción intelectual en torno a esa organización, sus líderes y acciones. La corriente más académica de esa producción intelectual será analizada en este trabajo, para diferenciarla de otras corrientes intelectuales más tecnopolíticas que tuvieron alguna influencia en la $\mathrm{AEASF}^{2}$.

La emergencia de un discurso o relato andinos proveniente de dirigentes de esta organización, como los alcaldes Gregorio Mendoza y Francisco Humire, de General Lagos y Putre, respectivamente, que iba más allá del asistencialismo local, llamó profundamente la atención. Discursos o relatos que parecían proyectarse hacia un espacio más amplio, transfronterizo, porque no estaban dirigidos hacia las comunidades sino hacia las autoridades, fueran de los gobiernos regionales, nacionales u organismos internacionales.

En una entrevista realizada al alcalde y presidente de AEASF, Francisco Humire Alejandro, en febrero 2008, nos señalaba que:

"Se tenía muy en claro que, sin una organización poderosa desde la periferia, nuestros problemas no tendrían forma de hacerse notar. Desde la capital o desde el extranjero se tiene la idea de que Chile es un país en desarrollo y esas cosas, pero no es así en las zonas extremas. Por ejemplo, en estos momentos en General Lagos, Colchane y Ollagüe los municipios están peleando por tener 24 horas de energía eléctrica -actualmente solo tiene por 3 horas. Entonces cuando las exigencias rayan en las necesidades básicas hay que tomar cartas en el asunto...".

"A pesar de estos problemas concretos, no descuidamos el pasado y nuestras reivindicaciones como pueblo, estamos muy conscientes que, a nivel comunal y a nivel territorial, cada municipio y cada alcalde tiene y enfrenta problemas concretos que tienen que ver con la pobreza y marginalidad. Si nosotros como autoridades con ascendencia e identidad indígena aymara no somos capaces de atacar y solucionar estos problemas, es difícil que otra persona sin esta visión regional lo haga".

"Nuestra labor de alcaldes nos hace -por la naturaleza de nuestro cargo- tener una visión regional y tener conciencia plena de los problemas de nuestras comunidades. Ahora no es novedad que las autoridades rurales tengan la noción de macrorregión, entonces si las particularidades de la zona aymara son las mismas en los tres países, el sentido común nos lleva a buscar soluciones comunes para la región aymara".

"Cuando comenzamos, la visión que tenía era incomprendida. Muchas veces el Concejo Municipal puso trabas como no aprobar platas para realizar viajes a Bolivia o al Perú. No había una visión de integración, había un encapsulamiento hacia lo meramente local. Además, existía una desconfianza de lo que efectivamente se podía lograr con la Alianza".

Algunos autores observaron el surgimiento de un "nuevo trato" de los tres Estados nacionales con los habitantes indígenas de la triple frontera y la zona fronteriza circunvecina, llegando a concluir que estaríamos incluso frente a una "paradiplomacia aymara" (Aranda y Salinas 2017), lo que significaría la existencia de una capacidad de negociación a escala internacional muy relevante, y con la institucionalidad necesaria para implementarla. En cierta forma, implicaría también la creación de una región andina transfronteriza (de facto y no de jure) con identidad reconocida. La idea del surgimiento de una "paradiplomacia" en zonas de frontera ya había sido adelantada por José Luis Rhi-Sausi y Nahuel Oddone, cuando señalaban que:

La integración regional y el desarrollo de una gobernanza transfronteriza estimulan un papel creciente de la paradiplomacia. Los especialistas de las relaciones internacionales encontraron en el término paradiplomacia el marco conceptual para 
analizar, encuadrar y explicar este nuevo fenómeno de la participación internacional de los municipios y otras unidades subestatales (2013:273)

No es extraño que estos autores hayan pensado en esa la posibilidad de cierta autonomía, porque la paradiplomacia, siguiendo a Hocking, "más allá de las condiciones domésticas que explicaban la participación de dichos entes subestatales en la esfera internacional, los cambios provocados por la globalización han sido el motor primordial que han impulsado a estos entes a desarrollar una acción exterior" (1993:36). Y la globalización se expresaría en ese territorio con la presencia del Banco Mundial, el Banco Interamericano de Desarrollo, grandes Compañías Mineras, ONG, etc. Aranda y Salinas afirman que "la Alianza Estratégica Aymaras Sin Fronteras se consolidó notoriamente de forma que fue capaz de atraer y captar la atención de numerosos actores internacionales, convirtiéndose en destinataria de abundantes fondos de la cooperación internacional..." (2017:101).

Por otra parte, también algunos autores han podido observar la utilización -por parte de los dirigentes aymaras- de la frontera como posición estratégica, en el sentido que habitar la triple frontera tendría un valor geoestratégico para los gobiernos regionales y nacionales, así como para organizaciones internacionales, especialmente con relación al control de los flujos negativos que suelen cruzar las triples fronteras, donde la "del Paraná" ha sido el referente explicativo de este imaginario de "temor a la triple frontera"

\section{“(...) proliferación del contrabando de diverso tipo, multiplicación de tráficos ilegales (armas, drogas, personas), presen- cia de terrorismo de origen variado (desde células dormidas de $\mathrm{Al}$ Qaeda hasta visitas de las FARC) (Giménez 2011:10).}

La transformación de este temor en poder político podría implicar un mayor acceso al poder real. Al respecto, Laetitia Rouviere, afirma:

"A partir de las experiencias de la AEASF nuevos canales de diálogo entre centros y periferias se abrieron, sobre todo en Chile y en Bolivia. Los alcaldes empiezan a participar en los comités de frontera bilaterales; en el 2007 se crearon los Encuentros entre Municipios Fronterizos Bolivia-Chile, encuentros anuales financiados por las dos cancillerías y donde participan cada vez más funcionarios centrales..." (2014:49).

Sin embargo, como en esa metáfora de Michel Foucault sobre el espejo como un espacio-otro y utopía (1967), definir a la triple frontera como un espacio de glocalización y paradiplomacia, es mirar a un lugar que existe, pero no es en rigor real. No se puede negar la existencia de la globalización, la cooperación internacional, los flujos negativos, los proyectos integrados, etc., pero bastaría viajar a la triple frontera para constatar que allí esos procesos no han llegado a las comunidades indígenas. La imagen que se retrata en el discurso de los dirigentes de la AEASF y que recogemos los académicos, como la imagen en un espejo, parece ser la realidad, pero no reflejan la población de pastores andinos. Esa imagen, al menos no existe a escala local. Fenómenos tales como la "glocalización" no solamente aún no se expresan en el territorio, sino que todavía no se han superado las atávicas condiciones de marginalidad social y pobreza. Sumado a un elemento relevante: los comuneros no desean necesariamente ese tipo de cambio social y cultural propio de la sociedad y cultura occidentales.

\section{¿La Alianza Estratégica Aymaras Sin Fronteras surge ex nihilo?}

En el tripartito las fronteras se diluyen ante la altura, el frío, el viento y ese paisaje altiplánico de violenta belleza enmarcada por volcanes, donde los Payachatas $^{3}$ son la expresión máxima de lo señalado. Al mirar hacia los cuatro costados el paisaje expresa un escenario indisolublemente unido y coherente, donde solo impactan la basura que dejan los camiones que transitan las rutas internacionales aledañas y los modernos productos de las zonas francas de Iquique y de Tacna, yuxtapuestos a los tradicionales de la feria andina que se organiza cada quince días. Allí se dan cita los habitantes de pequeñas comunidades vecinas y emparentadas, pero que tienen de tres nacionalidades distintas: Ancomarca, peruana; Charaña, boliviana; Visviri, chilena. Se entremezclan los tradicionales productos altiplánicos y de precordillera como papa chuño, quinua, charqui, harinas, etc., con otros venidos de 
ultramar como relojes, calculadoras, televisores, computadores, neumáticos, etc. Esta feria es una réplica en miniatura de la feria del Alto La Paz, pero que nos indica que el mercado internacional ha llegado hasta los más recónditos rincones del planeta (Polanyi 1992). A pesar de lo anterior, según Daniel Bello, siguiendo los datos del PNUD y el análisis de Scott Bailey, el territorio de la AEASF se encuentra en los linderos inferiores de desarrollo humano, comparado con cualquier otro país de América Latina (2012, p. 160).

Iniciado el siglo veintiuno parecía que había llegado una nueva época, supuestamente gracias a la oportunidad que la globalización y la descentralización les otorga en estos días a los espacios tradicionalmente marginales y dominados, sin llegar a ser un Pachakuti, para los habitantes de la triple frontera caracterizados por la pobreza y la discriminación históricas ${ }^{4}$, mediante la emergencia (aparentemente endógena) de la Alianza Estratégica Aymaras Sin Fronteras (AEASF).

El interés por definir una zona trifronteriza con propósito de integración y cooperación entre Perú, Bolivia y Chile se inició hace décadas, según Nilo Meza Monge "el antecedente más lejano de este enfoque lo encontramos en el seminario internacional 'Bolivia, Chile y Perú: hacia un modelo cooperativo trinacional', realizado a mediados de 1977, en La Paz, con el apoyo de la Corporación Andina de Fomento. Uno más reciente es la publicación del libro Hacia un enfoque trinacional de las relaciones entre Bolivia, Chile y Perú (2001), también auspiciado por la CAF" (Meza 2005:42). Entre los primeros intelectuales que pensó en una zona de integración trinacional como un proyecto compartido de desarrollo fue Ricardo Anaya, sociólogo boliviano, en su libro Arica Trinacional: Bolivia, Chile y Perú (1987).

Esas iniciativas, a pesar del enfoque trinacional, se ubican en la escala o nivel de los Estados nacionales y sus relaciones vecinales; en cambio, el fenómeno que se puede identificar en la zona circunvecina al tripartito de Ancomarca, se ubica en la escala de las comunidades y sus relaciones transfronterizas tradicionales, cuyas raíces se hunden en los periodos precolombino y colonial.

Como antecedente de estos cambios que se visibilizan al inicio del siglo veintiuno, Aranda y Salinas hacen mención de la Campaña Internacional por los 500 Años que surgió en 1992, especialmente "en Bolivia, Guatemala, Ecuador y México, pero también hay debates en países con menor población como Colombia, Brasil y Chile" (2015:162). En el plano académico, un hito fue el encuentro de investigadores (especialmente peruanos, bolivianos, argentinos y chilenos) en la localidad de San Pedro de Atacama entre el 26 y 30 de octubre de 1992, para abordar "los quinientos años" (Albó et al. 1996). Ya, entonces, el cambio de regímenes militares en el Cono Sur de América, la recuperación de la democracia, la apertura de las economías y la globalización cultural señalaba un notorio optimismo entre los académicos al conmemorarse el "descubrimiento de América" que pasaba a llamarse "encuentro de dos mundos": "no pretendíamos simplemente marcar un hito histórico, sino más bien buscábamos identificar la relevancia de nuestras respectivas labores, puesto que estamos en el umbral del siglo XXI, nuestros países están encaminados en procesos redemocratizantes y las relaciones norte-sur van modificándose de acuerdo a las nuevas estructuraciones de los mercados internacionales" (Albó et al. 1996:13).

Resulta evidente que entonces nadie podía imaginar el surgimiento en el tripartito andino de un fenómeno como el de la Alianza Estratégica Aymaras Sin Fronteras. A pesar de que, como bien lo señala Laetitia Rouviere, la base de esta organización son los municipios rurales, creados en 1979, organismos que "aparecieron en el marco de la doctrina de seguridad nacional con el objetivo de consolidar la soberanía estatal, tanto a nivel interno como externo. Aquello permitió a la Junta militar instaurar un control estrecho sobre los espacios y poblaciones potencialmente disidentes (2014:42). ¿Por qué no podría pensarse en la AEASF, como una forma de securitización en la frontera? (Treviño 2016).

Por otra parte, a escala de la región de Arica y Parinacota, las demandas sociales relacionadas a la problemática indígena surgieron inmediatamente iniciada la democracia, antes de la promulgación de la ley indígena. En enero de 1991 se celebró en Arica el II Congreso de la Comisión Especial de Pueblos Indígenas (precursora de la CONADI ${ }^{5}$ ):

Representantes de comunidades aymaras de las provincias de Arica, Parinacota e Iquique participarán en el II Congreso de la Comisión Especial de Pueblos Indígenas convocado para culminar la discusión del "Borrador de la Nueva Ley Indígena", tarea 
que se viene desarrollando desde tres meses

(La Estrella de Arica 5 de enero 1991).

En paralelo a esta iniciativa, una voz venida desde el mismo Tripartito Andino era recogida por el mismo diario. Se trataba de la voz de Fortunato Manzano Manzano. Se indica que se trata de un aymara de 60 años, fundador del pueblo de Visviri. $\mathrm{El}$ argumento es el siguiente:

Don Fortunato es aymara y heredó de sus antepasados una extensión de terrenos cerca de la estación del Ferrocarril. El pueblo fue fundado en 1960. Primero fue la escuela y más tarde comenzaron a levantar las casas en los terrenos de la sucesión "Miguel Manzano Choque", según consta en la escritura del año 1942, número 361 , página 106 , terrenos que también están inscritos en el Archivo Nacional y que fueron cedidos para la construcción de viviendas, dada la cercanía con la escuela pública, el retén de Carabineros y la estación del Ferrocarril.

Fortunato Manzano Manzano también tramitó la creación de la escuela de Visviri, hizo realidad la fiesta del 3 de mayo, construyó la capilla y reorganizó el Carnaval. En 1960 este ciudadano chileno enviaba al subdelegado de General Lagos un completo plan de trabajo para mejorar el caserío, incluyendo la donación de un terreno para construir una nueva escuela, decidieron hacer un camino de Visviri a Caquena, la ampliación de los bofedales para la crianza de auquénidos, habilitación de una turbina para aprovechar las aguas del río Putane, habilitar una cancha de aterrizaje de emergencia, construir una policlínica, una oficina para el Registro Civil, sede social y biblioteca, multicancha, entre otras obras que impulsó hace treinta años este descendiente aymara (La Estrella de Arica 9 de enero de 1991).

El reclamo se refiera a la a cobranza de SERVIU por los terrenos donde levantaron sus casas los habitantes de Visviri. Tal como lo veremos más adelante para el caso de la AEASF, parece que la dirigencia aborda una problemática y los pobladores otra.
La AEASF supuestamente se organizó con el propósito de buscar recursos financieros externos para desarrollar proyectos de desarrollo que fueran en directo beneficio de las comunidades indígenas que habitan la zona fronteriza de los tres países. Han sido 57 municipios los que han participado activamente en esta Alianza. El hecho que hayan sido municipios (Albó et al. 2002) este proceso sería sistémico, es decir, un proyecto que se implementaría dentro de la institucionalidad jurídico-política de los tres países.

Este fenómeno comenzó a surgir en una zona geográfica compleja, ubicada sobre los tres mil metros de altura sobre el nivel medio del mar y además fronteriza, abarcando cientos de kilómetros desde el Tripartito de la meseta de Ancomarca, por el norte, hasta la tierra de los Lípez, por el sur. Se trataba del diálogo entre comunidades aymaras (locales) transfronterizas y estas a su vez con organismos regionales, nacionales e internacionales (globales). No tardó este diálogo en llamar la atención de ONG preocupadas de la cooperación internacional, como CESPI ${ }^{6}$, pero sobre todo interesó a académicos, investigadores y tesistas, dispuestos a poner a prueba sus hipótesis y teorías recientes acerca de lo local/global, especialmente a partir de autores como Manuel Castells, Jordi Borja y otros ${ }^{7}$.

Varias tesis han sido inspiradas por la AEASF, como la de Scott P. Bailey, para Máster en Políticas Públicas de la Escuela de Gobierno John F. Kennedy de la Universidad de Harvard, o la tesis doctoral de Laetitia Rouviere, en el Instituto de Estudios Políticos de la Universidad de Grenoble, Francia. Las investigaciones comenzaron a publicarse mediante artículos en revistas de corriente principal, donde ha prevalecido la mirada del cambio cultural, social y político en un territorio caracterizado por la marginalidad y la pobreza. La frontera comenzó a ser vista como un recurso político y las comunidades indígenas vistas como agentes de cambio ${ }^{8}$.

Incluso se ha planteado, siguiendo a Michel de Certeau', que estos espacios son heterológicos y los investigadores deberían rescatar la voz de los aymaras frente a la globalización ${ }^{10}$ y los otros espacios/escalas de poder.

¿Por qué los investigadores, en general, pensaron en un escenario optimista? La repuesta podría estar en lo señalado por Jessop:

“(...) encontramos que nuevos lugares están emergiendo, nuevos espacios están siendo 
creados, nuevas escalas de organización están siendo desarrolladas y nuevos horizontes de acción están siendo imaginados" (...) considerando que como respuesta a este desafío “(...) muchas estrategias están siendo desarrolladas para vincular estas y otras escalas a lo global -incluyendo la internacionalización, triadización, formación de bloques regionales, construcción de redes de ciudades globales, formación de regiones transfronterizas, localización internacional, glocalización, glurbanización y transnacionalización (...)-" (2004:90).

También Noé Cornago nos dice que las

"transgresiones, que cuestionan la territorialización que hace el Estado de las fronteras a través de políticas de contención territorial, se abren hacia subjetividades no estatales, como es el caso de grupos étnicos, elites económicas y gobiernos subnacionales, quienes propician 'otras voluntades de desterritorialización”” (2013, p. 9) ${ }^{11}$.

Este mismo autor nos señala además que:

"el discurso que despliegan organismos tales como el Fondo Monetario Internacional o el Banco Mundial, cuando en sus informes periódicos se refieren, respectivamente, a las expectativas de crecimiento, o a la reducción de la pobreza (...) parecen reforzar la idea de un mundo capaz de dialogar, cuya garantía reside en el fortalecido papel de la organización internacional" (2013:16).

Precisamente, son organismos como el Banco Mundial los que se aproximaron a la AEASF para ayudarle financieramente en sus proyectos de desarrollo. En otras palabras, la expresión territorial de fenómeno conocido como "glocalización".

Aranda y Salinas concluyen que este fenómeno de glocalización podría tener un impacto positivo en la diplomacia entre los tres países (Bolivia, Perú y Chile), porque sería una verdadera plataforma de integración trinacional:

La viabilidad integracionista que tendrá esta alianza, que como producto del litigio entre Chile y Bolivia en la Corte de
La Haya ha dejado de ser cooperativa y casi inexistente, dependerá además de los aspectos económicos, sociales, políticos, culturales y físicos de las estrategias, planes y aspiraciones que los miembros de la Alianza Estratégica Aymaras Sin Fronteras desarrollen (2017, p. 103) $)^{12}$.

La acción de los alcaldes rurales andinos, todos integrantes de la AEASF, se adaptaron rápidamente a la oferta financiera para nuevos proyectos venida desde los gobiernos regionales y nacionales, y de organismos internacionales, pero reproduciendo las relaciones de poder verticales conocidas. Por lo anterior, es que los pobladores de las comunidades fronterizas han reaccionado en contra de sus autoridades municipales. El periódico electrónico El Morrocotudo del 27 de mayo de 2008, señala:

El 16 de mayo de 2008, en el tripartito frontera Perú-Chile-Bolivia, los alcaldes de Charaña, Palca y General Lagos de Bolivia, Perú y Chile, respectivamente, realizaron una Feria de Camélidos Sud Americanos, que causó el descontento de las comunidades aymaras del lugar. Cada uno de los alcaldes dispuso de cada una de sus arcas municipales, más de cien mil dólares para un festejo donde las comunidades no han ganado nada.

Recordemos que las comunidades de criadores de alpacas y llamos de la zona, el 16 de junio de 1996 decidieron por voluntad soberana constituir el "PARLAMENTO DEL PUEBLO QOLLANA AYMARA "PPQA" para defenderse de los saqueos de agua de que son víctimas por parte de los proyectos gubernamentales que pretende secar los bofedales de las comunidades alto andinas -donde pastan sus alpacaslugar cuyo nombre original es " $Q$ 'euña Wichinca”, despojándoles sus aguas, perforando túneles, desbrozando canales para llevarse el agua y otros, hechos que tanto daño viene causando a la economía de dichas comunidades.

Pero, los alcaldes de las municipalidades arriba señaladas, haciendo oídos sordos a estos justos reclamos, organizan fiestas de jolgorio y se llenan la boca anunciando "proyectos productivos sostenibles" para 
las comunidades. Preguntamos ¿Qué de productivo puede tener la desecación de los bofedales que son la base para la alimentación y calmar la sed de nuestras alpacas y llamas? Veamos: En el discurso de inauguración de dicha feria, estuvo presente el Sr. Gregorio Mendoza, Alcalde de General Lagos, que en Arica dijo que es "difícil criar alpacas en estas altura" pero en los hechos nada está haciendo por proteger a sus comunidades de los desecamientos de los bofedales en su jurisdicción causados por las sustracciones de agua subterránea en los Pozos del Ayro, nada está haciendo por los efectos que van a sufrir sus comunidades, al explotarse el oro por parte de la Compañía MINSUR S.A. del Perú. Sin embargo, dice "trabajaremos unidos" es decir "alcaldes unidos juntos trabajemos para destrozar las comunidades".

El otro alcalde, el de Charaña, Víctor Hugo Apaza Mamani, dijo que está presente su Viceministro de Agricultura de apellido Gonzáles, y el Mallku Félix Brutón, afirmó "Nuestro Objetivo es la llama y la alpaca" pero en los hechos, nunca reclamó por el desvío del Río Maure, que ya no llega hasta las tierras de pastoreo de Charaña. Él oculta una verdad ante su pueblo; que son cómplices de la llamada "Autoridad autónoma del lago Titicaca" que autoriza ilegalmente la desecación de bofedales. El alcalde de Palca, Aureliano Gutiérrez, quedó muy mal y parado cuando leyó su discurso (seguramente redactado por un mal asesor) y dijo textualmente "estamos haciendo proyectos productivos sostenibles" varios le pifiaron, fue en ese momento que el Regidor Basadre, enviado por el alcalde Provincial de Tacna, se retiró de la reunión raudamente, dejando a todos los alcaldes distritales con los crespos hechos y desairados. Más tarde, dijo el regidor que estando a la altura de Calientes recibió una llamada a su teléfono celular, del alcalde provincial de Tacna, Luis Torres Robledo, donde le dijo: "Si ya te has retirado, diles que tendrán las puertas abiertas de mi municipio, pero para el próximo año" en son de burla, como diciendo nunca, ya que dicho alcalde es pro minero convicto y confeso.
Deben saber estos alcaldes, aves de paso, que las comunidades del tripartito, desde 1996 hemos decidido volver a nuestra matriz Qollana Aymara, que ya no les creemos a esas autoridades producto de la colonización, que hemos vuelto a nuestro AYMAR MARKA JACHA ULAKA y que aunque ellos, los alcaldes, se gasten los miles de dólares que nosotros tributamos, no van a tapar el sol con un dedo. Estamos desprotegidos, no estamos contentos con sus alcaldías, nosotros queremos que nuestros Jilakatas vuelvan a tomar autoridad en nuestros territorios, porque queremos cuidar nuestra madre tierra, no queremos que se siga saqueando nuestras aguas superficiales y subterráneas, porque son sagradas para nosotros y porque queremos llegar a nuestras futuras generaciones un provenir de paz y alegría verdadera para todos.

Esta noticia quebró en mil pedazos el espejo donde se reflejaba la Alianza Estratégica Aymaras Sin Fronteras (AEASF) frente a los investigadores y académicos, como un miraje que desaparece a los ojos escrutadores de quienes -obnubilados por el fenómeno de la globalización- olvidaron el origen histórico de los municipios rurales en Perú, Bolivia y Chile, cuando en la década de 1980, bajo regímenes autoritarios, reemplazaron a las Asambleas Comunales y los alcaldes a los Jilakatas (Gundermann 2006).

La idea de un territorio sin fronteras no necesariamente ha emergido desde la globalización, autores como Carla Rodas, en sus trabajos de terreno, ha recogido esta perspectiva desde las propias comunidades indígenas, como el caso de Curahuara de Carangas en Bolivia, muy próxima al tripartito, a saber:

Asimismo los aymaras de Curahuara de Carangas conciben un territorio como un espacio que se reproduce y como una tierra sin fronteras:

"el aymara es un pueblo sin fronteras, no discriminemos a los chilenos, a los argentinos, que los peruanos, que los ecuatorianos, sino todos somos aymara [...] el territorio aymara es como cualquier persona o animalito, para crecer se nace, se relaciona y luego se tienen hijos" (X 35, 2013, entrevista). (2016:12). 


\section{Conclusiones}

A la triple frontera andina, donde confluyen Perú, Bolivia y Chile, sostenemos, investigadores la han visto como un espacio-otro, un espejo llamado Alianza Estratégica Aymaras Sin Fronteras, donde se reflejan las comunidades aymaras viviendo el siglo veintiuno bajo el fenómeno de la glocalización, la cooperación internacional y la existencia de proyectos transfronterizos integrados, bajo una lógica de seguridad trinacional. Sin embargo, la imagen del espejo no es nítida respecto de esa realidad, por tanto solo son municipios y una elite político-administrativa que sustentan un discurso, mientras las comunidades siguen viviendo el lento y persistente proceso de desarraigo hacia las ciudades, mientras los indicadores de pobreza y marginalidad se mantienen.

La Alianza Estratégica Aymara Sin Fronteras en cierta forma fue como la imagen heterotópica de un espejo, porque refleja una imagen del mundo andino que parece una realidad, pero que exactamente no lo es, lo que resulta evidente cuando se escuchan las voces que están a la escala de lo efectivamente local, como las unidades territoriales aymaras tradicionales, como el ayllu (Medinacelli, 2012: 29). Además, esta organización no surgió ex nihilo porque es posible identificar diversos antecedentes, tanto desde las propias organizaciones indígenas (Cepi, Conadi) como desde la institucionalidad estatal (municipios).

No se puede negar la existencia del fenómeno de los flujos negativos como el contrabando, el narcotráfico, el terrorismo internacional, las migraciones irregulares, etc., movilizados por organizaciones criminales internacionales que, sin duda, han transformado a las fronteras y las triples fronteras en particular, en un espacio geoestratégico que es preciso controlar por medio de la cooperación en todas las escalas. En cambio, los deseados flujos positivos, como el rescate del patrimonio, el turismo integrado, los corredores bioceánicos, los proyectos de desarrollo transfronterizos, etc., movilizados por organismos internacionales con apoyo gubernamental y municipal, donde las comunidades indígenas sean las principales beneficiadas, todavía no se expresan a escala local o de las comunidades. Los campesinos indígenas, a pesar de todo, siguen silenciados e invisibilizados al margen heterológico de la triple frontera.

\section{Referencias Citadas}

Albó, X. y Quispe, V.

2002 ¿Quiénes son indígenas en los gobiernos Municipales? Editorial Plural, La Paz.

Albó, X.; Arratia, M.I.; Hidalgo, J.; Núñez, L.; Llagostera, A.; Remy, M.I.; Revesz, B. (Comp.)

1996 La integración surandina cinco siglos después. CBC, UCN, CNG, Talleres Gráficos del Centro Bartolomé de Las Casas, Cuzco.

Amilhat Szary, Anne-Laure

2009 "Ruralité, ethnicité et montagne: le référent andin dans le projet de territoire 'aymaras sin frontera"'. Revue de Géographie Alpine 2, 137-148.

Anaya, R.

1987 Arica Trinacional: Bolivia, Chile y Perú. Editorial Los Amigos del Libro, La Paz.

Aranda, G. y Salinas, S.

2015 "Aymaras y mapuches, paradiplomacia y acción colectiva transnacional". Cuadernos Americanos 154, 153-183.

Aranda, G. y Salinas, S.

2017 "Paradiplomacia aymara: empoderamiento en la frontera". Estudios Fronterizos 18, Vol. 35, 90-106.

Bello, D.

2012 "Alianza Estratégica Aymaras sin Fronteras: Una respuesta territorial a los desafíos de la "glocalización"”. Revista T'inkazos 32,147-164.
Boisier, S.

2003 "Globalización, Geografía política y Fronteras". Anales de Geografía de la Universidad Complutense 23, 21-39.

Borja, J. y Castells, M.

1997 Local y Global. La gestión de las ciudades en la era de la información, Barcelona: Editorial Taurus.

Castells, M.

2005 Globalización, desarrollo y democracia: Chile en el contexto mundial, México: Fondo de Cultura Económica.

Certeau, M.

2000 La invención de lo cotidiano I. Artes de hacer, México: Universidad Iberoamericana/Instituto Tecnológico de Estudios Superiores de Occidente (ITESO).

Cornago, Noé

2013 Breviario de postestructuralismo para internacionalistas, en:http://www.academia.edu/2286259/ Breviario_de_posestructuralismo_para_internacionalistas. Giménez, V.

2011 "La 'triple frontera' y sus representaciones. Políticos y funcionarios piensan la frontera", Frontera Norte, Vol. 23. $\mathrm{N}^{\mathrm{o}} 46,7-34$.

González, S.

2006 Densidad, integración y conflicto en la triple frontera (Perú, Bolivia, Chile), Bogotá: Serie integración social y fronteras. Convenio Andrés Bello. 
González, S.

2015 "La voz desde lejos. La triple frontera andina entre la heterología y la globalización”, Revista Andamios, Vol. 12, $\mathrm{N}^{\circ} 28$, mayo-agosto, 19-41.

González, S.; Rouvière, L. y Ovando, C.

2008 "De 'Aymaras en la frontera' a 'Aymaras sin fronteras': los gobiernos locales de la triple-frontera andina (Perú, Bolivia y Chile) y la globalización", Dialogo Andino, № 31 , 31-46.

Jessop, R.

2004 "La economía política de la escala y la construcción de las regiones transfronterizas", EURE, mayo vol. 30, $\mathrm{N}^{\circ} 89$.

Gundermann, $\mathrm{H}$.

2006 "Municipios y pueblos indígenas en Chile". En: Assies, W. y Hocking, B. Localizing Foreign Policy. NonCentral Governments and Multilayered Diplomacy. Ed. MacMillan Press, London.

Medinacelli, X.

2012 "Paisaje en movimiento. Turco y la erupción del Huayna Putina". En: Turco marka. Hombres, dioses y paisaje en la historia de un pueblo orureño. Historia-arqueologíaarquitectura, Ximena Medinacelli (coord.). Editorial IEB, La Paz, 21-47.

Meza, $N$

2005 "Zonas de integración fronteriza (ZIF) Perú-Bolivia, una experiencia a considerar", Revista Aldea Mundo Vol. 10, $\mathrm{N}^{\mathrm{o}} 18,36-43$.

Moncayo, E.

2002 "Glocalización: Nuevos enfoques teóricos sobre el desarrollo regional (subnacional) en el contexto de la integración económica y la globalización". Revista Desafíos, Vol. 7, 50-99.

Polanyi, K.

1992 La gran transformación. Los orígenes políticos y económicos de nuestro tiempo, México: F.C.E.

Rhi-Sausi, J.L. y Oddone, N.

2013 "Integración regional y cooperación transfronteriza en los nuevos escenarios de América Latina", Investigación y Desarrollo $\mathrm{N}^{\circ} 21, \mathrm{~N}^{\circ} 1,260-285$.
Rodas, C.

2016 Libres y sin fronteras: Dos casos de luchas indígenas por el territorio en el Chaco (comunidad Guaraní de Ivo) y en el Altiplano (marka Aymara de Curahuara de Carangas) de Bolivia. Instituto Francés de Estudios Andinos. https:// ifeanet.academia.edu/

Rouvière, $\mathrm{L}$.

2014 "Gobernar territorialidades transfronterizas. Seguridad y 'desarrollo con identidad' aymara en la triple frontera del norte de Chile (Chile-Perú-Bolivia)", Trace, № 65, 37-50.

Rouvière, L.

2009 “¿Un territorio político transfronterizo? Formas de legitimación de una experiencia de legitimación de una experiencia de acción política intermunicipal", Si Somos Americanos Revista de Estudios Transfronterizos, $\mathrm{N}^{\circ}$ 9, Vol. 2, 13-29.

Rouvière, L.

2008 “Una difusión descentralizada del modelo chileno? Municipios andinos y políticas de desarrollo en la triple frontera 'aymara' (Chile-Perú-Bolivia)". Nuevo Mundo, Mundos Nuevos $\mathrm{N}^{\circ}$ 8. http://journals.openedition.org/ nuevomundo/11122; DOI: 10.4000/nuevomundo.11122

Treviño, J.

2016 “De qué hablamos cuando hablamos de la 'securitización' de la migración internacional en México?: una crítica. Foro Internacional 224, LVI, 253-291.

Wong-González, P.

2005 "Regiones y redes territoriales emergentes ante la globalización y la virtualización de la economía”. Ruta Crítica, revista de la Universidad de Sonora s/ $\mathrm{N}^{\circ}, 38-41$.

\section{Fuentes}

Entrevista a Francisco Humire (agradecimiento al profesor Rodrigo Ruz).

Periódico digital El Morrocotudo.

Diario La Estrella de Arica.

\section{Notas}

1 La AEASF fue creada por 57 municipios de los tres países, reunidos en las siguientes organizaciones: Asociación de Municipios Rurales de Tarapacá (Chile, Regiones I y XV), Asociación de Municipios Rurales Andinos de Tacna (AMRAT, Perú), Mancomunidades de La Paz, Oruro y los Lípez-Potosí (Bolivia).

2 Especialmente intelectuales que han tenido papeles en organismos estatales relacionados, como fue el caso de Nilo Meza Monge en Perú. En el caso chileno, hubo especialistas de la Subsecretaría de Desarrollo Regional (SUBDERE) que apoyaron a la AEASF.

3 Se refiere a los dos volcanes gemelos: Parinacota y Pomerape.

4 Nos hemos referido a este tema en otros trabajos anteriores. González, S. "La voz desde lejos. La triple frontera andina entre la heterología y la globalización", Revista Andamios, Volumen 12, número 28, mayo-agosto, 2015, pp. 19-41.

5 Corporación de Desarrollo Indígena. Organismo estatal sin rango de ministerio.
6 Centro Studi di Politica Internazionale, Roma-Italia.

7 Castells, M. (2005). Globalización, desarrollo y democracia: Chile en el contexto mundial. Chile: Fondo de Cultura Económica.

Borja, J. y Castells, M. (1997) Local y Global. La gestión de las ciudades en la era de la información. Editorial Taurus. Moncayo Jiménez, E. (2002). "Glocalización: Nuevos enfoques teóricos sobre el desarrollo regional (subnacional) en el contexto de la integración económica y la globalización". Revista Desafíos, Vol. 7, 50-99.

$8 \quad$ Meza Monge, Nilo (2005). “Zonas de Integración Fronteriza (ZIF) Perú-Bolivia, una experiencia a considerar". Revista Aldea Mundo, mayo, Vol. 10, No 18, Universidad de Los Andes, San Cristóbal, Venezuela, 36-43.

González Miranda, Sergio (2006). Densidad, integración y conflicto en la triple frontera (Perú, Bolivia, Chile), Serie Integración Social y Fronteras. Convenio Andrés Bello, Bogotá. 
Rouviere, Laetitia (2007). “¿Un territorio político transfronterizo? Formas de legitimación de acción política intermunicipal entre Bolivia, Chile y Perú (BCP): el caso de la Alianza Estratégica Aymaras Sin Fronteras". Revista Parinas, Vol. 3, $\mathrm{N}^{\circ} 1$ INTE-UNAP.

Rouvière, L. (2008). “¿Una difusión descentralizada del modelo chileno? Municipios andinos y políticas de desarrollo en la triple frontera 'aymara' (Chile-Perú-Bolivia)", Nuevo Mundo, Mundos Nuevos $\mathrm{N}^{\circ} 8$.

Amilhat Szary, Anne-Laure (2009). "Ruralité, ethnicité et montagne : le référent andin dans le projet de territoire 'aymaras sin frontera"', Revue de Géographie Alpine, $\mathrm{N}^{\circ} 2$, 137-148.

Bello, Daniel (2012). “Alianza Estratégica Aymaras Sin Fronteras. Una respuesta territorial a los desafíos de la globalización". Revista T'ínkazos $\mathrm{N}^{\circ} 32,147-164$.

González Miranda, Sergio, Rouvière, Laetitia, Ovando, Cristian (2008). "De 'Aymaras en la frontera' a 'Aymaras sin fronteras': los gobiernos locales de la triple-frontera andina (Perú, Bolivia y Chile) y la globalización", Dialogo Andino, $\mathrm{N}^{\circ} 31,31-46$.
Zapata S., Claudia (2007). "Memoria e historia. El proyecto de una identidad colectiva entre los Aymaras de Chile", Chungara, Revista de Antropología Chilena, vol. 39, № 2, 171-187.

Rouviere, Laetitia (2009). “¿Un territorio político transfronterizo? Formas de legitimación de una experiencia de legitimación de una experiencia de acción política intermunicipal", Si Somos Americanos, Revista de Estudios Transfronterizos, $\mathrm{N}^{\circ}$ 9, Vol. 2, 13-29.

9 Certeau, M. (2000). La invención de lo cotidiano I. Artes de hacer, Universidad Iberoamericana / Instituto Tecnológico de Estudios Superiores de Occidente (iteso), México.

10 González, S. (2012). "La voz que viene de lejos. La triple frontera andina, entre la heterología y la globalización". ANDAMIOS, Vol. 12, № 28.

11 Cornago, Noé (2013). "Breviario de postestructuralismo para internacionalistas", en: http://www.academia.edu/2286259/ Breviario_de_pos-testructuralismo_para_internacionalistas, p. 9.

12 Op. cit., p. 103. 
